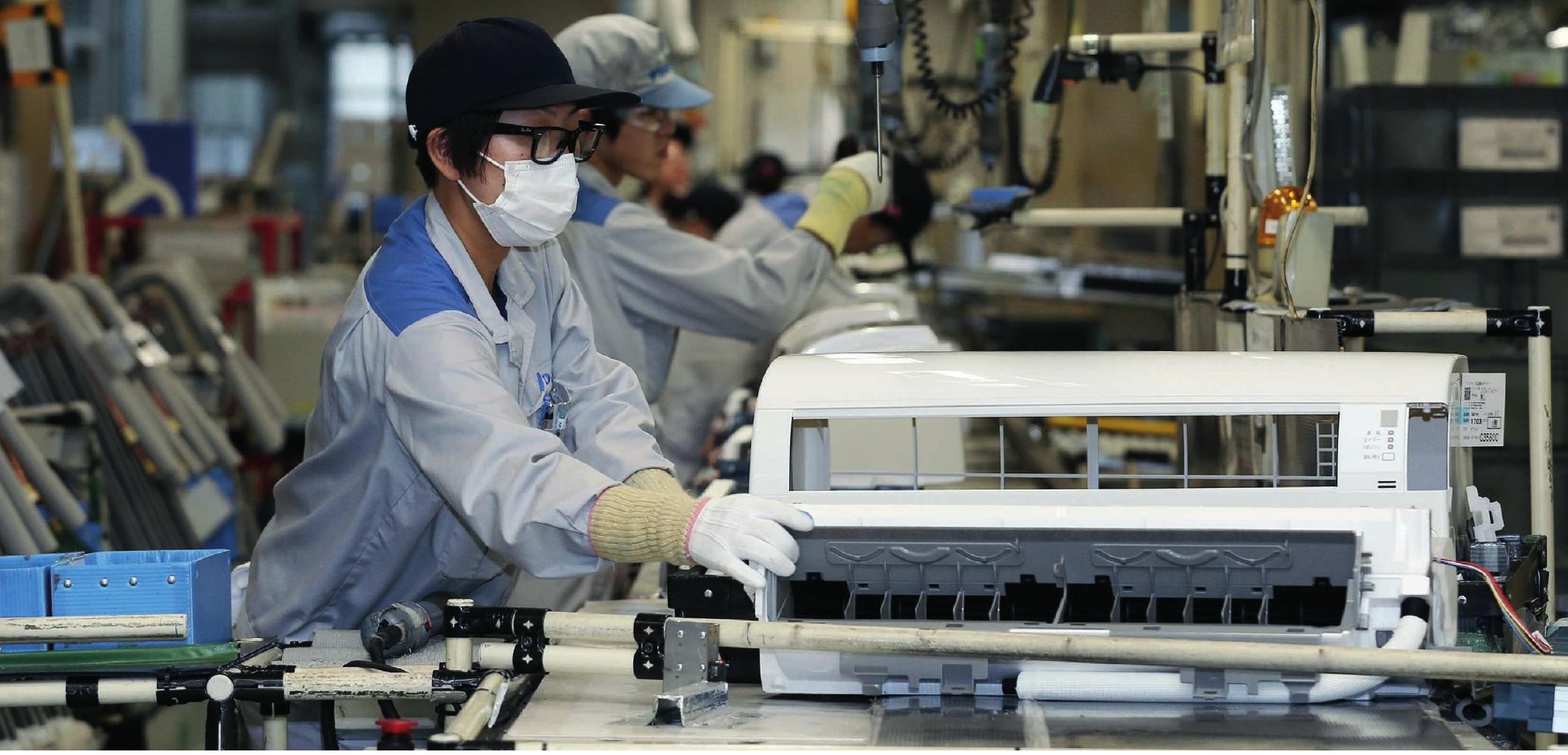

Daikin has enlisted the expertise of researchers at Osaka University in its quest to apply artificial intelligence to its air conditioners.

\title{
PARTNERS IN DISCOVERY
}

\section{Osaka University bets on commercial-academic collaborations to survive.}

\section{BY ICHIKO FUYUNO}

$\mathrm{O}$ saka University's strategy for longterm sustainability in the face of shrinking government funding emphasizes a new model of collaboration with industry based on the "co-creation of values", says its president, Shojiro Nishio.

Partnerships have historically involved a university responding to a company's wish list, he explains. But companies confronting rapid societal change now seek collaboration with university experts across a wider spectrum, and in the very earliest stages of research, from discussing themes and identifying market opportunities, to training engineers and discovering drugs.

At a time when government budgets for fundamental research and staff are shrinking, Nishio claims Osakàs model for industry -academic collaborations is "the solution to strengthen innovative capacity for universities."

Osaka came top among Japanese universities for innovation in the Nature Index, ranked according to the Lens Influence Metric which measures the influence of scholarly articles on patents. It is 4th among Japanese universities when assessed on its number of partnerships with Japanese companies that have resulted in publications between 2012 and 2017. Since 2006, it has set up nearly 70 offices and laboratories on campus for joint research with companies.

Nishio took office in 2015, and made it his mission to revitalize the university's ties with industry. In April 2017, he restructured the industry relations office to offer comprehensive support, from exploiting research ideas to patent management.

While the number of collaborative projects between universities and companies in Japan has grown from 15,544 in 2010 to 20,821 in 2015 , only $3.9 \%$ of them received more than 10 million yen (US\$90,000) from companies, according to Ministry of Education, Culture, Sports, Science and Technology. Under Nishio's leadership, Osaka has signed several large contracts with companies.

In May 2016, Chugai Pharmaceutical agreed to provide one billion yen (US\$9 million) over 10 years for Osaka University's Immunology Frontier Research Center (IFReC). Government funding for the institute, under the World Premier International Research Center Initiative, ceased that year. IFReC can spend the recent influx of funds on the operation of the centre at its discretion. In return, Chugai researchers can join discussions and experiments, as well as have a first look at outcomes. IFReC has signed a similar 10-year contract to give Otsuka Pharmaceutical a second look at outcomes.

In June 2017 Daikin Industries, which is finding ways to apply artificial intelligence to its flagship air-conditioning products, agreed to invest 500 million yen (US\$4.5 million) in Osaka University, every year, for 10 years. More than 20 selected young engineers have since transferred from the company to Osakass campus, and are discussing themes for joint research. Meanwhile, Panasonic, the electronics manufacturer, has jointly developed a curriculum with the university to teach artificial intelligence and its commercial application.

Nishio has also convinced Daikin and Biken Foundation, the university's research foundation for microbial diseases, a spin-off specializing in vaccines development, to support employment of promising young researchers for the next decade. Four researchers have already been employed under the plan and Nishio hopes to increase the number to 30 .

\section{ON A RAIL}

Osaka has a history of successful ties to industry. In 1967, it launched Japan's first automated train ticket gates, jointly developed with electronics company, Omron, and the private rail services, Kintetsu and Hankyu.

Research at Osaka into interleukin 6, a protein that regulates the immune system, led to the development, along with Chugai, of tocilizumab, a drug used to treat rheumatoid arthritis, among other diseases. In 2016, researchers at Osaka and the medical devices company, Terumo, launched HeartSheet, the world's first regenerative medicine product designed to treat heart failure. Osaka’s recent industrial alliances are aimed at achieving similar success. 